\title{
Timing Variations in Two Balkan Percussion Performances
}

\author{
DANIEL GOLDBERG[1] \\ Yale University
}

\begin{abstract}
Many songs and dance pieces from the Balkan Peninsula employ aksak meter, in which two categorically different durations, long and short, coexist in the sequence of beats that performers emphasize and listeners move to. This paper analyzes the durations of aksak beats and measures in two recorded percussion performances that use a particular aksak beat sequence, long-short-short. The results suggest that the timing of beats varies in conjunction with factors including melodic grouping and interaction among members of a performing ensemble and audience. Timing variation linked to melodic groups occurs on a solo recording of a Macedonian Romani folk song. The performer, Muzafer Bizlim, taps an ostinato while singing, and the timing of his taps seems to mark some local and large-scale group boundaries. Melodic organization also seems relevant to the timing of beats and measures on a recording of Bulgarian percussionist Mitko Popov playing the tüpan, a double-headed bass drum, in a small folk music ensemble. In Popov's performance, however, timing differences might be related to characteristics of the ensemble dynamic, such as the coordination of multiple musical participants. These interpretations generate possibilities for future study of timing variations in relation to rhythm and meter.
\end{abstract}

Submitted 2014 December 8; accepted 2015 September 23.

KEYWORDS: Balkan, aksak, timing, rhythm, meter, performance, percussion

\section{AKSAK RHYTHM}

AUDIO Example 1 is a recording of a Romani folk song from Macedonia. The song is called "Bešli i čaj tele" after its first line, and the lyrics describe a girl's decision about which man to marry.[2] In some respects, this recording is not the most typical example of Balkan folk music performance. It was made and released on CD by human rights activist Gregory Scarborough to aid the Macedonian Romani community following the conflict in Kosovo of the late 1990s (Scarborough, 2000). The performer is a songwriter and author named Muzafer Bizlim who lives in Šuto Orizari, a large Romani neighborhood in Skopje, Macedonia, and during the recording session he sat on the floor of his home and accompanied his own singing by tapping an ostinato on the top of a stack of books (Scarborough, personal communication).[3]

The repeating rhythm that Bizlim plays throughout the recording demonstrates a feature of many songs and dance pieces from southeastern Europe: the coexistence of categorically different durations in the sequence of beats that performers emphasize and listeners move to. Adopting a term that twentiethcentury Romanian ethnomusicologist Constantin Brăiloiu (1984, p. 133) drew from Turkish musical vocabulary, I refer to this type of rhythmic organization as aksak. Other terms that have been applied to the phenomenon include additive rhythm, neravnodelen razmer or "unequally divided meter," and nonisochronous meter (Sachs, 1953; Dzhudzhev, 1980; London, 2012). While the theoretical approaches corresponding to these names differ substantially from one another, they typically describe temporal cycles composed of durations belonging to two different categories, long and short, in a ratio of 3:2. Brăiloiu (1984) and his Bulgarian coeval Stoyan Dzhudzhev (1931, 1980) sought to systematize the possible combinations of short and long beats and identify their properties, a project that a handful of authors have continued more recently (e.g., Arom, 2004; Cler, 1994; London, 2012). In music from southeastern Europe, common aksak sequences include short-long, short-short-long, long-short-short, short-short-short-long, and short-short-long-short-short.

Within this framework, the tapped rhythm in Bizlim's performance of "Bešli i čaj tele" could be thought of as articulating a long-short-short aksak sequence. Often, long durations are notated as lasting for 
three eighth notes and short durations for two, leading to a transcription with seven eighth notes in a measure as in Figure 1. Note that I intend this figure and subsequent transcriptions as rough sketches of rhythm to provide a shared visual point of reference; accordingly, I omit time signatures and have made no attempt to notate the exact timing, ornamentation, or other details, despite the importance of such details.[4] Bizlim's ostinato, for example, includes two groups of quick, light strokes that are notated in Figure 1 as grace notes.

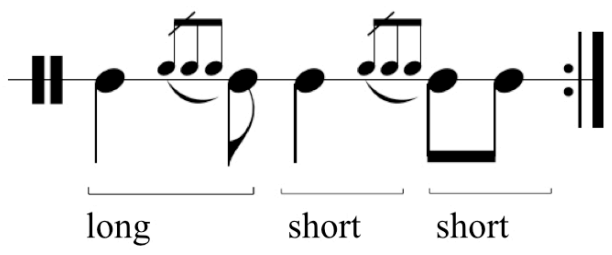

Figure 1. A transcription of the tapped ostinato in "Bešli i čaj tele," labeled with the durations of the longshort-short aksak sequence.

The present paper examines details of the timing with which such aksak sequences are performed by analyzing a pair of recordings of Balkan folk music. I follow musicians, dancers, and listeners, especially Americans, in applying the phrase "Balkan folk music" to a collection of musical styles from southeastern Europe that are associated with traditional music-making through characteristics of both sonic material and performance context.[5] While this phrase glosses over many important distinctions, it is consistent with the concept of a "Balkan Musikbund" that is shared among some of the peoples and regions of southeastern Europe (Keil, Keil, Blau, \& Feld, 2002, pp. 96-102; Pettan, 1996, p. 35).

After introducing some general features of Balkan folk music with one type of aksak sequence, I use basic statistical methods to quantify and compare the timing of aksak onsets as played by individual percussionists. This analysis addresses the two recordings in turn, highlighting a different factor with which timing appears to vary in each case. The first example, Bizlim's “Bešli i čaj tele," exhibits differences in aksak timing in connection with regular phrases and other melodic groups, while the second, an ensemble performance with drumming by Bulgarian musician Mitko Popov, demonstrates timing changes that might relate to coordination among the performing musicians and members of the audience. The choice of recordings is intended to offer a stylistically and culturally contrasting pair of performances that might hint at the range of Balkan folk music practice; to my knowledge neither is musically exceptional.

My approach throughout this study is exploratory in the sense of searching freely for possible patterns in the timing data, so the results that I report need to be treated with caution, as the basis for planning future tests of much larger samples.[6] The work belongs to a research project that aims to characterize the timing component of musical style and to improve understanding of the relationship between details of timing in rhythmic performance and ways in which that timing is perceived and conceived, especially with regard to musical meter.

\section{BACKGROUND}

American scholars and performers of Balkan music and dance have reported a qualitative flexibility in the relative durations of certain aksak sequences. In particular, Rice (2000, pp. 205-206) describes timing changes that occur in conjunction with increasing tempo in performances of a type of dance with a longshort-short-long-short aksak sequence, often called beranče or pušteno oro. Other experienced American dancers and musicians including Michael Ginsburg (personal communication) and David Golber (personal communication) also single out beranče with regard to variable timing, describing how the exact durations that a musician plays traditionally depend on the movements of the lead dancer.

Music psychologists have long been aware that performed durations often differ systematically from mental and notated representations of rhythm (see, e.g., Bengtsson \& Gabrielsson, 1977; Clarke, 1985; Repp, 1992, 1998a), but very few previous authors have measured the exact durations between notes in aksak cycles. Moelants (2006, p. 167) finds considerable variety in analyzing the average timing of long and short aksak durations in a selection of 11 commercial recordings of Bulgarian folk music, concluding that the relationship between long and short durations does not conform to a stable ratio, but rather differs 
with factors including the aksak sequence, the particular dance tune, and the individual performer. In a similar study of excerpts from commercial recordings of Greek folk songs with a long-short-short aksak sequence, Peninta, Cambouropoulos, and Papadelis (2008) identify a statistically significant tendency for the second of the three durations in the sequence to be shorter than a strict long-to-short ratio of 3:2 would predict, and for the third duration to be longer than predicted.

As a step toward further quantifying the variability of performed timing in aksak sequences and identifying factors that might affect this timing, I limit the present analysis to examples of the long-shortshort sequence demonstrated in "Bešli i čaj tele." This sequence is among the most frequently used aksak cycles in several styles of folk music from Macedonia and western Bulgaria; indeed, American percussionist and dancer Helen Marx (personal communication) regards it as the most typical Balkan rhythm, and when I began studying percussion technique with Macedonian Romani instrumentalist Željo Destanovski, long-short-short was the first aksak sequence that he taught me.[7] Moreover, for many listeners and performers this sequence carries nostalgic or nationalistic associations with Macedonian culture (Silverman, 2012, p. 162).[8]

My study of timing is based on interonset intervals, or IOIs, from one musical event to another. In "Bešli i čaj tele," for example, I match the long-short-short sequence by measuring IOIs between the beginnings of the first, third, and fourth main taps in each measure, omitting the other two taps and the notated grace notes in Figure 1. Throughout this paper I confine such timing measurements to performances by individual percussionists, for both conceptual and practical reasons. Like many other performances in the styles I consider, the two present recordings feature a single drum, and many participants regard this instrument as the timekeeper for musicians and dancers alike. Furthermore, the sounds of drum strokes are the easiest type of onset to pinpoint in analyzing an audio recording.

To identify these onset times as precisely as possible, I use a combination of close listening and tapping along with the recording, audio editing and analysis software, and original computer code. Specifically, I begin by using onset detection plugins in the program Sonic Visualiser (Cannam, Landone, \& Sandler, 2010) to mark onset times automatically. These plugins do not work perfectly, so I run the onset detection repeatedly with different settings and then employ simple Python code to combine the results by selecting the time points that are likely to be closest to actual onsets. Next I identify the notes I want to study by tapping along as the recording plays, and again use code to select those tapped onsets from the set of automatically detected onsets, a procedure inspired by Craig Sapp's Tap Snap tool (http://mazurka.org.uk/cgi-bin/tapsnap). Finally, I check the resulting series of onsets manually by listening to the recording and looking at the waveform.

The book that Bizlim taps on is an unusual kind of percussion instrument; much more common in ensemble performances of Balkan folk music is the tüpan, a large, double-sided bass drum.[9] Players typically hold the drum at waist level using a shoulder strap and hit one side with a wooden beater and the other side with a thin, flexible switch.[10] In my experience taking tŭpan lessons, Macedonian, Bulgarian, and American players have all taught standard series of drum strokes to articulate a given aksak sequence or accompany a particular melody; these templates can then be varied, embellished, or abandoned in performance. The most basic stroke pattern that I was taught for a measure with a long-short-short sequence consists of beater strokes on the downbeat and the beginning of the first short aksak duration, alternating with switch strokes on the third eighth note and the beginning of the second short duration. Figure 2 transcribes this pattern with a simplified version of the notation system that Bulgarian tüpan player Mitko Popov uses when teaching.

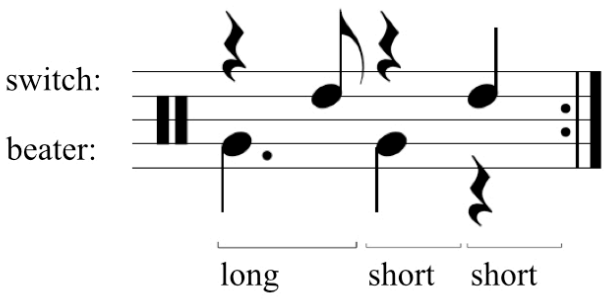

Figure 2. A transcription of the basic tŭpan stroke pattern for a long-short-short sequence. Notes with downward stems are played with the beater, and notes with upward stems are played with the switch. 
A brief consideration of how the long-short-short sequence interfaces with meter is necessary before delving into rhythm and timing on particular recordings. Following Justin London (2012), I adopt a psychological perspective whereby meter is a mental construct that aids performers and listeners in producing and perceiving musical events in time; the durations among these events are rhythm. As London (2012, p. 2) explains, for a performer, meter serves to "guide ... the motor behaviors used in the production of musical sounds," while for a listener, meter enables dancing and other potential movements in coordination with music by providing expectations for when musical events will occur. Music theorists often model metric cycles in terms of two or more coordinated temporal levels, each of which consists of a series of time points.[11] Using the style of representation established by Lerdahl and Jackendoff (1983), Figure 3 adds these levels to the transcribed ostinatos from "Bešli i čaj tele" and tŭpan pedagogy, such that each horizontal row of dots represents time points on a single level. For future reference, I label three of the temporal levels as the subtactus, the beat, and the measure, corresponding in this case to the beginnings of notated eighth notes, of quarter notes and dotted quarter notes, and of spans between barlines. Note that meters could include more or fewer levels than those that are named and shown here. Regardless of the number of levels in a meter, though, the beat occupies a privileged position as the single level that tends to stand out most strongly in the experience of the performing musician, dancer, or listener using the meter. I refer to someone with any of these possible roles as a "musical participant." In addition, although the terms "measure" and "bar" are associated with notation, here I use them in relation to a musical participant's metric experience, to refer to the level that most strongly modularizes or begins the cycle of time points on the beat level.
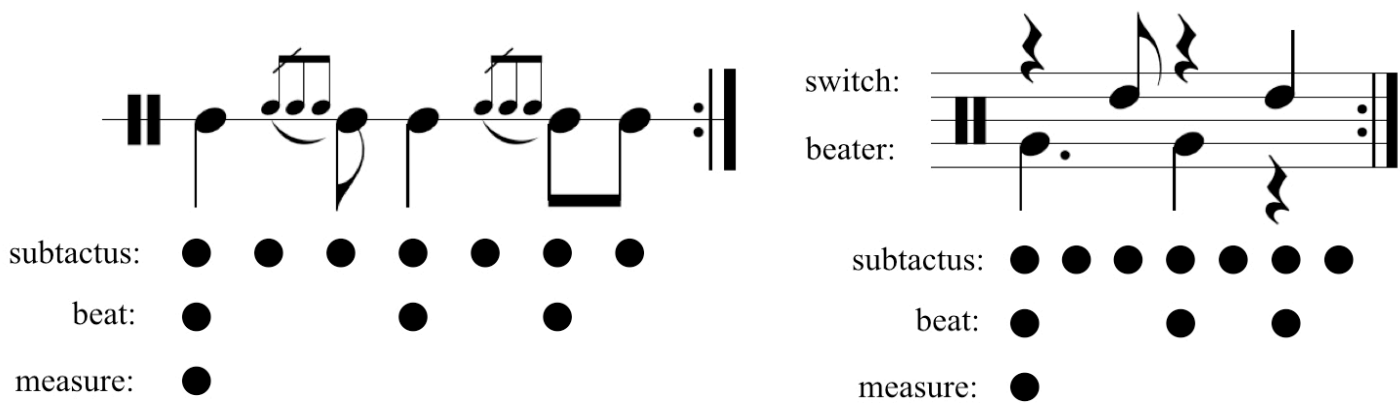

Figure 3. The transcriptions from Figures 2 and 3, annotated with metric levels.

\section{MUZAFER BIZLIM, “BEŠLI I ČAJ TELE”}

The primary goal of my analysis is to establish that differences in aksak timing exist within performances of Balkan folk music, and that these differences might relate to other musicologically relevant aspects of the performance. Bizlim's rendition of "Bešli i čaj tele" provides an initial example of such fine-grained variations, and the following discussion presents patterns in his average beat IOIs and then focuses on interpreting these patterns in relation to melodic groups. Again following common usage derived from Lerdahl and Jackendoff (1983), I refer to a group as a perceived segment of successive musical events.[12] In the context of the present article a phrase is a group of intermediate length, typically four to eight measures, that ends with a sense of closure; however, the groups that I call phrases do not necessarily fit definitions of a phrase in western art music such as Lerdahl and Jackendoff's (1983, p. 134) conditions for the harmonic structure of a phrase.

As outlined in Table 1, Bizlim performs the song strophically, setting each of the six verses with two repeated melodic lines for a total of four four-measure phrases per verse. The two melodies, labeled A and $\mathrm{B}$, change minimally over the course of the recording, most noticeably through slight rhythmic alterations to match the number of syllables in a line of text. Bizlim also taps for two measures before each verse; these two-bar segments are identified as the transition because of their dual role in concluding one verse and preparing the next. 
Table 1. Melodic organization of "Bešli i čaj tele."

\begin{tabular}{|c|c|c|c|}
\hline Section & Phrase & $\begin{array}{l}\text { Number of } \\
\text { Measures }\end{array}$ & $\begin{array}{c}\text { Start Time on } \\
\text { Audio Example } 1\end{array}$ \\
\hline Transition & & 2 & $0: 02$ \\
\hline \multirow[t]{4}{*}{ Verse 1} & $\mathrm{~A}$ & 4 & $0: 06$ \\
\hline & $\mathrm{A}$ & 4 & $0: 13$ \\
\hline & $\mathrm{B}$ & 4 & $0: 20$ \\
\hline & B & 4 & $0: 26$ \\
\hline Transition & & 2 & $0: 33$ \\
\hline \multirow[t]{4}{*}{ Verse 2} & $\mathrm{~A}$ & 4 & $0: 36$ \\
\hline & $\mathrm{A}$ & 4 & $0: 43$ \\
\hline & B & 4 & $0: 49$ \\
\hline & $\mathrm{B}$ & 4 & $0: 56$ \\
\hline Transition & & 2 & $1: 02$ \\
\hline \multirow[t]{4}{*}{ Verse 3} & A & 4 & $1: 06$ \\
\hline & $\mathrm{A}$ & 4 & $1: 12$ \\
\hline & $\mathrm{B}$ & 4 & $1: 18$ \\
\hline & B & 4 & $1: 25$ \\
\hline Transition & & 2 & $1: 32$ \\
\hline \multirow[t]{4}{*}{ Verse 4} & A & 4 & $1: 35$ \\
\hline & A & 4 & $1: 41$ \\
\hline & $\mathrm{B}$ & 4 & $1: 48$ \\
\hline & B & 4 & $1: 54$ \\
\hline Transition & & 2 & 2:01 \\
\hline \multirow[t]{4}{*}{ Verse 5} & A & 4 & $2: 04$ \\
\hline & A & 4 & $2: 11$ \\
\hline & $\mathrm{B}$ & 4 & $2: 17$ \\
\hline & B & 4 & $2: 23$ \\
\hline Transition & & 2 & $2: 30$ \\
\hline \multirow{4}{*}{ Verse 6} & A & 4 & $2: 33$ \\
\hline & $\mathrm{A}$ & 4 & $2: 39$ \\
\hline & $\mathrm{B}$ & 4 & $2: 46$ \\
\hline & B & 4 & $2: 52$ \\
\hline
\end{tabular}

\section{Variations in Beat Timing}

The IOIs of the long-short-short sequence fluctuate in conjunction with the song's four-bar phrases, with the three IOIs on the beat level following different trajectories of lengthening and shortening. Figure 4 graphs the beat durations in each measure of the two melodically distinct phrases, averaged across the 12 occurrences of each phrase on the recording.[13] Vertical brackets surrounding the data points in the figure show standard deviations. In terms of statistical significance, determined by Tukey's HSD test following a one-way ANOVA, the mean IOI of the first beat is shorter in the fourth measure of each phrase than it is in the first three measures. The duration of the second beat varies less than that of the other two beats, as reflected in the comparatively short brackets and shallow angles of the purple line on the graph; however, the mean IOIs of this beat at its two peaks, the last bar of phrase A and the second bar of phrase B, are still significantly longer than the IOIs in the first and last measures of phrase $\mathrm{B}$. The third beat also has two peak durations, in the second and fourth bars of phrase A, which differ from the shorter average IOIs in the third bar of phrase A and the middle two bars of phrase B (see Appendix Table 1).[14] 


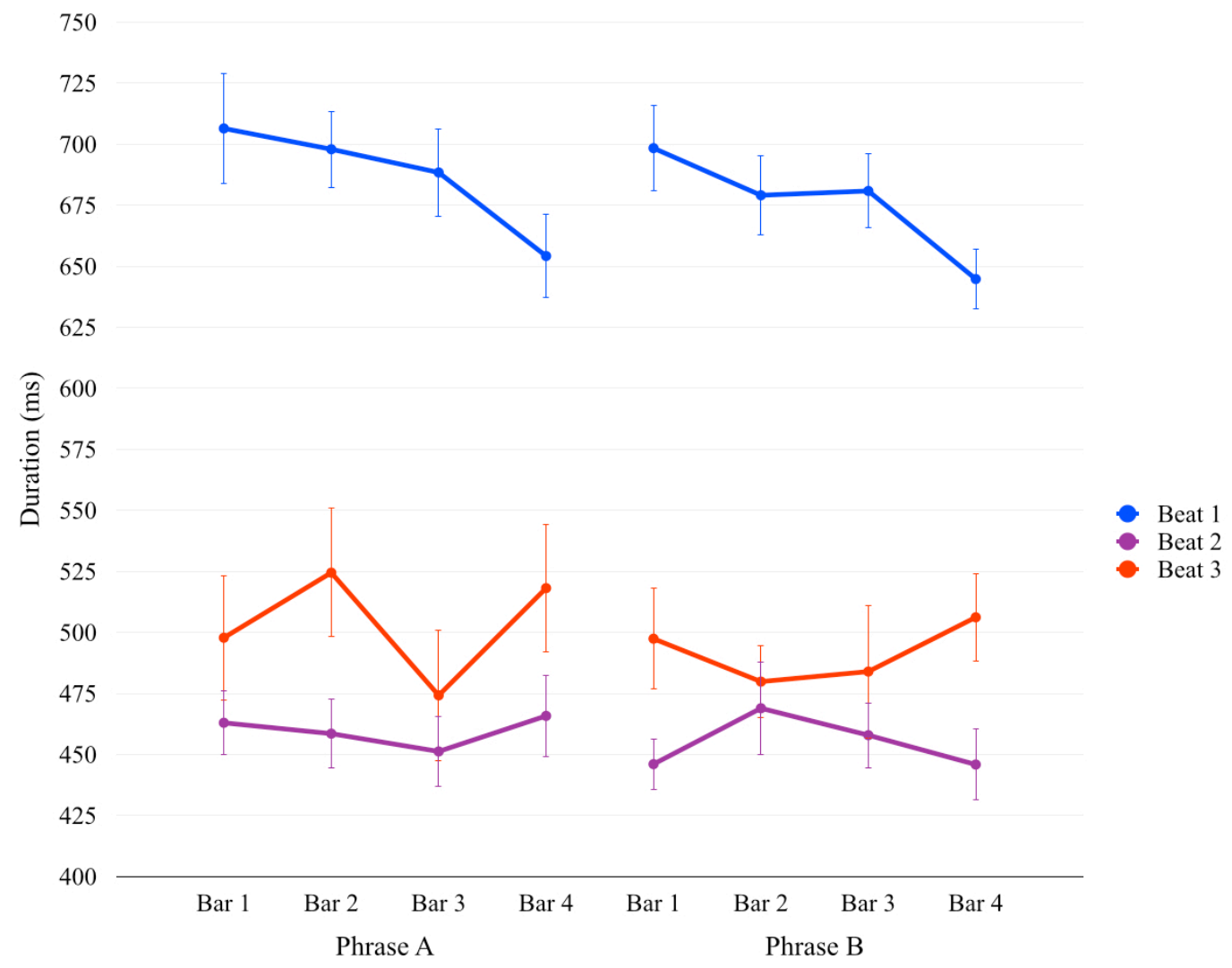

Figure 4. Mean beat IOIs in each bar of the two phrases of "Bešli i čaj tele." Vertical brackets show standard deviation.

Before continuing, it is important to note that the measurements of beat IOIs in milliseconds shown in Figure 4 are potentially sensitive to changes in the length of the measure. Other recent studies control for such changes by reporting beat IOIs in terms of proportions of the measure instead of milliseconds (e.g., Jankowsky, 2013; Polak \& London, 2014). However, converting IOI measurements into proportions creates interdependence among the values of the three beats, which violates an assumption of my statistical tests and makes relative lengthening more difficult to interpret. For example, if a beat's proportion of the measure increases, the change could result from an increase in that beat's IOI or a decrease in the IOI of the remainder of the measure.[15] I therefore confine most of my interpretation to durations in milliseconds rather than proportions. Particular changes in measure length are discussed below in connection with Figures 5, 6, and 7.

In addition to the changing IOIs of each beat over the course of the phrases, Figure 4 shows that the third beat is consistently longer than the second in Bizlim's performance, even though the second and third beats are nominally equivalent to each other in the sense that they are both categorized as short relative to the first beat. Pooling all measures of the performance together, the mean ratio of the second beat to the third beat is .92. A one-sample $t$-test indicates that this mean is significantly less than 1 , seemingly confirming the difference between the two beats (see Appendix Table 2).

These and the other statistically significant differences in timing discussed in this paper are quite small - on the bar-to-bar level shown in Figure 4, for example, the differences between mean IOIs of beats 2 and 3 range from about 23 milliseconds in the third bar of phrase A to about 66 milliseconds in the second bar of that phrase. Researchers studying performance timing have debated whether such minute differences are meaningful in light of the limitations of human hearing, proposing thresholds for perception ranging from 10 to $50 \mathrm{~ms}$ that likely depend on context (e.g., Benadon, 2007; Butterfield, 2007, 2010; Clarke, 1989). In a case comparable to the present situation, Polak (2010) used methods similar to my own 
to show that Malian djembe drummers play rhythms with three distinct average IOIs on the subtactus level in a short-medium-long sequence. Yet Neuhoff, Polak, and Fischinger (2014) subsequently demonstrated that the performers and dancers of this music perceive the sequence that Polak (2010) measured in terms of not three but two categories of relative metric durations, as short-long-long. Likewise, considering that participants in Balkan music generally recognize only long and short aksak categories, it seems quite possible that they would not notice the slight difference between the durations of the two short beats in "Bešli i čaj tele" or in other performances with similar timing. Nevertheless, I maintain that as long as researchers remain cognizant of the relationship with perception, a difference that cannot be reliably heard is still potentially noteworthy as a reflection of a consistent pattern in performers' actions. Assuming a close connection between what musicians play and what they hear, an imperceptible but robust difference in timing is arguably even of special interest because such a mismatch between musical production and perception could ultimately help to explain how both processes work.

\section{Timing and Groups}

The scope of the present study, however, allows only for speculation about possible factors affecting the observed differences in timing. One account of the difference between short beats, for example, involves the articulation of grouping boundaries. Studies of timing in performances of eighteenth- and nineteenthcentury compositions for solo piano have identified a tendency for performers to play increasingly longer durations as they approach the end of a phrase or other musical group (e.g., Gabrielsson, 1987; Ohriner, 2011; Repp, 1992; Todd, 1985). As in many pieces of Balkan folk music, I hear most of the local group boundaries in the melody of "Bešli i čaj tele" as coinciding with the boundaries of the aksak cycle, so this phenomenon, referred to as "group-final lengthening," seems plausible as a factor affecting the timing.[16] Of course, group-final lengthening is far from the only possible explanation; for instance, the timing pattern could result from the difference between the rhythms that Bizlim plays during the second and third beats, or from an underlying template that shapes his timing irrespective of grouping or rhythm.

Group-final lengthening might also influence changes in the duration of the third beat over the course of the two phrases, particularly the lengthening of the mean IOI in bar 2 of phrase A, a change that is conspicuously absent from bar 2 of phrase B. As listening to Audio Example 1 reveals, this difference corresponds to melodic grouping within the two phrases in Bizlim's performance. Bizlim emphasizes the grouping boundary in the middle of the first phrase, articulating the division of the phrase into two two-bar groups by taking a breath at the end of bar 2 . By contrast, he rarely breathes at this point in the second phrase, instead sustaining the note in the melody to project a stronger continuity across the four-bar span. The relative elongation of the third beat in bar 2 of phrase A might not contribute to a listener's conscious perception of grouping, but the variation in conjunction with a audible boundary nonetheless makes this timing pattern a candidate for group-final lengthening.

In addition to this local group boundary, the grouping of entire verses registers in Bizlim's timing, but in this case lengthening is clearest at the beginnings of groups rather than the ends. Figure 5 plots the IOI of each measure on the recording, adding the moving average of every four successive IOIs in order to smooth out local timing changes. The IOIs appear to grow shorter during the first 15 measures or so, and a one-way ANOVA indicates that the average bar IOI in the first verse differs significantly from the average in all other verses: there is a significant effect of a bar's verse on its IOI, $F(5,101)=8.26, p<.01$, and Tukey's HSD test finds that the only significant differences among the six means are between the first verse and each of the other verses. In light of the potential influence of bar length on beat measurements in milliseconds discussed above, the statistical tests linked to the beat IOIs in Figure 4 were repeated excluding measurements from the first verse. The results of the ad hoc test, reported in Appendix Table 1, are similar to the original results, suggesting that the significant differences interpreted above are not due simply to longer bar IOIs in verse 1. 


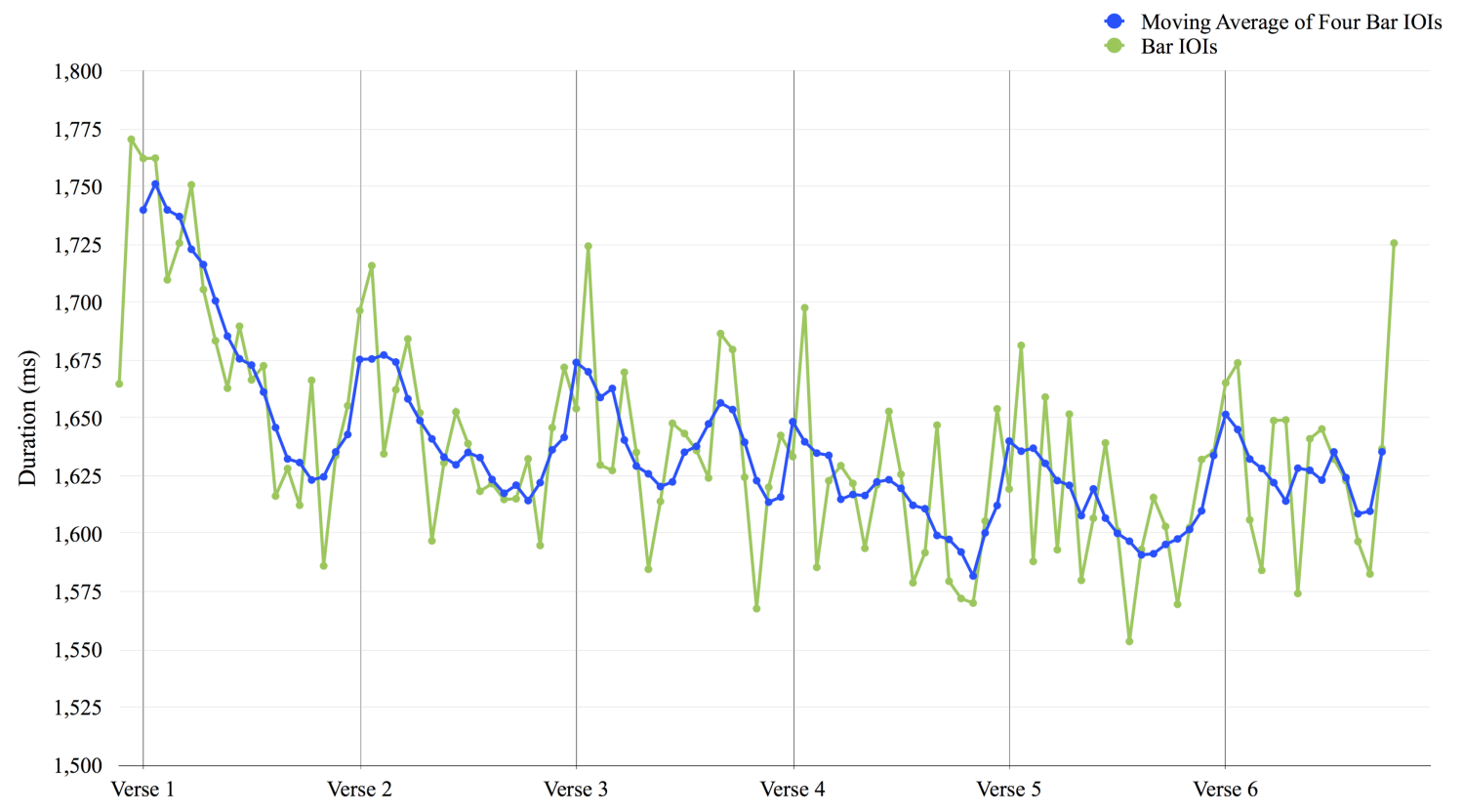

Figure 5. Individual bar IOIs in "Bešli i čaj tele" and the moving average of the IOIs of four successive bars. Vertical lines mark the beginning of each verse.

Apart from the longer measures in verse 1, the most noticeable pattern of bar IOIs across the recording as a whole is a peaking of durations that marks the beginning of each verse. I hesitate to use statistical tests to compare the mean bar IOIs among individual measures in a verse because the average for each of the 18 measures consists of only 6 observations. Still, the means corroborate the impression given by Figure 5, at least insofar as the longest and shortest means on this level are the second measure of the first time through phrase A $(M=1709 \mathrm{~ms}, S D=32 \mathrm{~ms})$ and the last measure of the second time through phrase B ( $M=1584 \mathrm{~ms}, S D=15 \mathrm{~ms}$ ). Most of the lengthening of bar IOIs leading to the beginning of a new verse thus seems to occur during the two-measure transition, in which the mean bar IOIs are $1634 \mathrm{~ms}$ $(S D=20 \mathrm{~ms})$ and $1672 \mathrm{~ms}(S D=50 \mathrm{~ms})$, respectively.

This pattern of longer durations at the start of a verse might seem to belie the expectation for group-final lengthening on the scale of large groups, and it is entirely possible that typical patterns of grouping-related timing in Balkan folk music will turn out to be quite different from those in the repertoire of solo keyboard music that has been the subject of most previous studies of the phenomenon.[17] However, Repp (1998b) finds that individual performers employ a considerable range of timing trajectories when playing the same short passage from a Chopin etude, with one of the most common models exhibiting lengthening at the beginnings instead of the ends of local groups. Ohriner (2011, pp. 40-45) also demonstrates that even performances with strong group-final lengthening do not necessarily display it on all durational spans and temporal levels, so the absence of lengthening on this particular level would be nothing unusual. In fact, in Bizlim's playing deceleration is audible at the end of the entire performance, a tendency that has been modeled as a special case of group-final lengthening (see Friberg, Bresin, \& Sundberg, 2006, pp. 149, 155-156). This slackening is mostly absent from the tapping measurements simply because Bizlim stops tapping on the downbeat of the last measure of phrase B.[18] Overall, then, the large-scale timing of Bizlim's bar IOIs certainly offers no evidence against the prevalence of groupfinal lengthening in Balkan music; a single example could hardly have done so. With respect to the present study's aim of identifying differences in timing, it is sufficient to note the appearance of any consistent timing variation linked to the span of the verse.

\section{MITKO POPOV, "NAZAD, NAZAD, MOME KALINO"}

Fluctuation in bar IOIs provides a useful starting point for comparison between "Bešli i čaj tele" and a second example of Balkan folk music, a performance that I recorded live at a workshop for intensive 
instruction in Bulgarian music and dance in July 2013. Organized annually at the Academy of Music, Dance, and Fine Arts in Plovdiv, Bulgaria, the weeklong seminar offers courses taught by Bulgarian musicians and dancers and attracts enthusiasts from abroad, especially western Europe and the United States.[19] The performance took place at a dinner party at the end of the week, during which a five-person ensemble of workshop instructors played favorite songs and seminar attendees danced and sang along at will.

Like most other members of the seminar's music faculty, the tŭpan player, Mitko Popov, studied music in the Bulgarian conservatory system. He currently serves as a percussionist, composer, and arranger for the Plovdiv-based Ensemble Trakiya, one of the premier Bulgarian groups dedicated to presenting the national styles of folk music and dance that evolved during the country's period of state socialism.[20] It is an idiosyncrasy of this system that tüpan is not taught in the conservatory alongside pitched folk instruments despite its essential role in the standard folk ensemble, so Popov's formal musical training is in a different instrument, classical contrabass.

Performers of Balkan folk music commonly create long medleys from a succession of multiple pieces in order to permit uninterrupted dancing, and the present recording, Audio Example 2, consists of one song excerpted from the middle of a medley that lasted for more than 20 minutes. In this piece as well as the rest of the medley, Popov plays continuously, using the tŭpan switch to articulate a nearly continuous stream of notes on the subtactus level - that is, the notated eighth note in the above transcriptions. Throughout the performance, dancing audience members held hands to form a line winding around the band and restaurant tables, using a common dance step for a long-short-short sequence called lesnoto. As in many Balkan dances, individuals may vary or elaborate the dance movements to a considerable extent without disturbing their neighbors, but the primary movements of the dance consist of a simple pattern of steps and leg lifts that mark the beginnings of the first two beats in any measure.[21]

The song, "Nazad, nazad, mome Kalino," is widely popular and associated with Macedonia and the southwestern region of Bulgaria, with versions of the lyrics in Macedonian and Bulgarian languages. The text enacts a conversation in which a woman insists on pursuing her former lover in spite of his protestations, and as sketched in Table 2, this text is set with two melodically differentiated groups labeled as phrases D and E. Unlike the two phrases in "Bešli i čaj tele," in "Nazad, nazad" the repeating units are each eight measures long, and only the second repeats immediately. Although the sections of lyrics alternate between chorus and verse, both types of text use the same melody.

Before each chorus or verse on the recording, the ensemble plays an instrumental interlude or break that Bulgarian musicians call an otsvir or pripev, creating a regular alternation between sections with and without singing.[22] When accompanying singing, the instrumentalists play softly and with comparatively few deviations from the familiar tune and accompanimental figures, and when taking over the melody during otsviri, they play more loudly and sometimes with more variations. Although otsviri may be largely improvised, "Nazad, nazad," as well as many other popular songs, has otsviri with a fixed melody that participants consider part of the song's identity (Buchanan \& Folse, 2006, p. 72).[23] In Table 2 , the two eight-measure groups of the precomposed otsvir are each labeled as phrase C, but since the halves of this phrase are melodically very similar, the section could be divided into four four-bar units instead. In any case, the instrumental break always concludes with a one-bar phrase expansion that delays the cadence immediately before the ensuing verse.

\section{Comparison between Performances}

Popov's performance evidently differs from "Bešli i čaj tele" in many respects, including the instruments and ensembles involved, the songs and their social functions, and the cultures and musical training of the performers, yet his playing bears some resemblance to Bizlim's in terms of the variation of bar IOIs. Figure 6 graphs individual measure IOIs in "Nazad, nazad" and their four-bar moving average just like Figure 5 did for "Bešli i čaj tele." Shifts between otsviri and vocal accompaniment are the most apparent changes in timing, and again, peaks in bar IOIs mark vocal entries. The differences among the mean bar IOIs of the three melodically distinct phrases, charted in Figure 7, are statistically significant, and their relationshipsshortest during the otsvir, longest during the first vocal phrase, and in between during the second vocal phrase - match the shape of the pattern in Figure 6.[24] Both performances, then, demonstrate modest but consistent changes in bar IOIs, occurring at similar points of articulation in large-scale melodic grouping. 
Table 2. Melodic organization of "Nazad, nazad, mome Kalino."

\begin{tabular}{|c|c|c|c|}
\hline Section & Phrase & $\begin{array}{l}\text { Number of } \\
\text { Measures }\end{array}$ & $\begin{array}{c}\text { Start Time on } \\
\text { Audio Example } 2\end{array}$ \\
\hline \multirow[t]{2}{*}{ Otsvir } & $\mathrm{C}$ & 8 & $0: 04$ \\
\hline & $\mathrm{C}$ & 9 & $0: 17$ \\
\hline \multirow[t]{3}{*}{ Chorus } & $\mathrm{D}$ & 8 & $0: 32$ \\
\hline & $\mathrm{E}$ & 8 & $0: 45$ \\
\hline & $\mathrm{E}$ & 8 & $0: 59$ \\
\hline \multirow[t]{2}{*}{ Otsvir } & $\mathrm{C}$ & 8 & $1: 12$ \\
\hline & $\mathrm{C}$ & 9 & $1: 25$ \\
\hline \multirow[t]{3}{*}{ Verse 1} & $\mathrm{D}$ & 8 & $1: 40$ \\
\hline & $\mathrm{E}$ & 8 & $1: 53$ \\
\hline & $\mathrm{E}$ & 8 & $2: 06$ \\
\hline \multirow[t]{2}{*}{ Otsvir } & $\mathrm{C}$ & 8 & $2: 19$ \\
\hline & $\mathrm{C}$ & 9 & $2: 32$ \\
\hline \multirow{3}{*}{ Chorus } & $\mathrm{D}$ & 8 & $2: 47$ \\
\hline & $\mathrm{E}$ & 8 & $3: 01$ \\
\hline & $\mathrm{E}$ & 8 & $3: 14$ \\
\hline \multirow[t]{2}{*}{ Otsvir } & $\mathrm{C}$ & 8 & $3: 27$ \\
\hline & $\mathrm{C}$ & 9 & $3: 40$ \\
\hline \multirow[t]{3}{*}{ Verse 2} & $\mathrm{D}$ & 8 & $3: 54$ \\
\hline & $\mathrm{E}$ & 8 & $4: 08$ \\
\hline & $\mathrm{E}$ & 8 & $4: 21$ \\
\hline \multirow[t]{2}{*}{ Otsvir } & $\mathrm{C}$ & 8 & $4: 34$ \\
\hline & $\mathrm{C}$ & 9 & $4: 47$ \\
\hline \multirow[t]{3}{*}{ Chorus } & $\mathrm{D}$ & 8 & $5: 02$ \\
\hline & $E$ & 8 & $5: 15$ \\
\hline & $\mathrm{E}$ & 8 & $5: 29$ \\
\hline \multirow[t]{2}{*}{ Otsvir } & $\mathrm{C}$ & 8 & $5: 42$ \\
\hline & $\mathrm{C}$ & 9 & $5: 55$ \\
\hline \multirow[t]{3}{*}{ Verse 3} & $\mathrm{D}$ & 8 & $6: 09$ \\
\hline & $\mathrm{E}$ & 8 & $6: 23$ \\
\hline & $\mathrm{E}$ & 8 & $6: 36$ \\
\hline
\end{tabular}




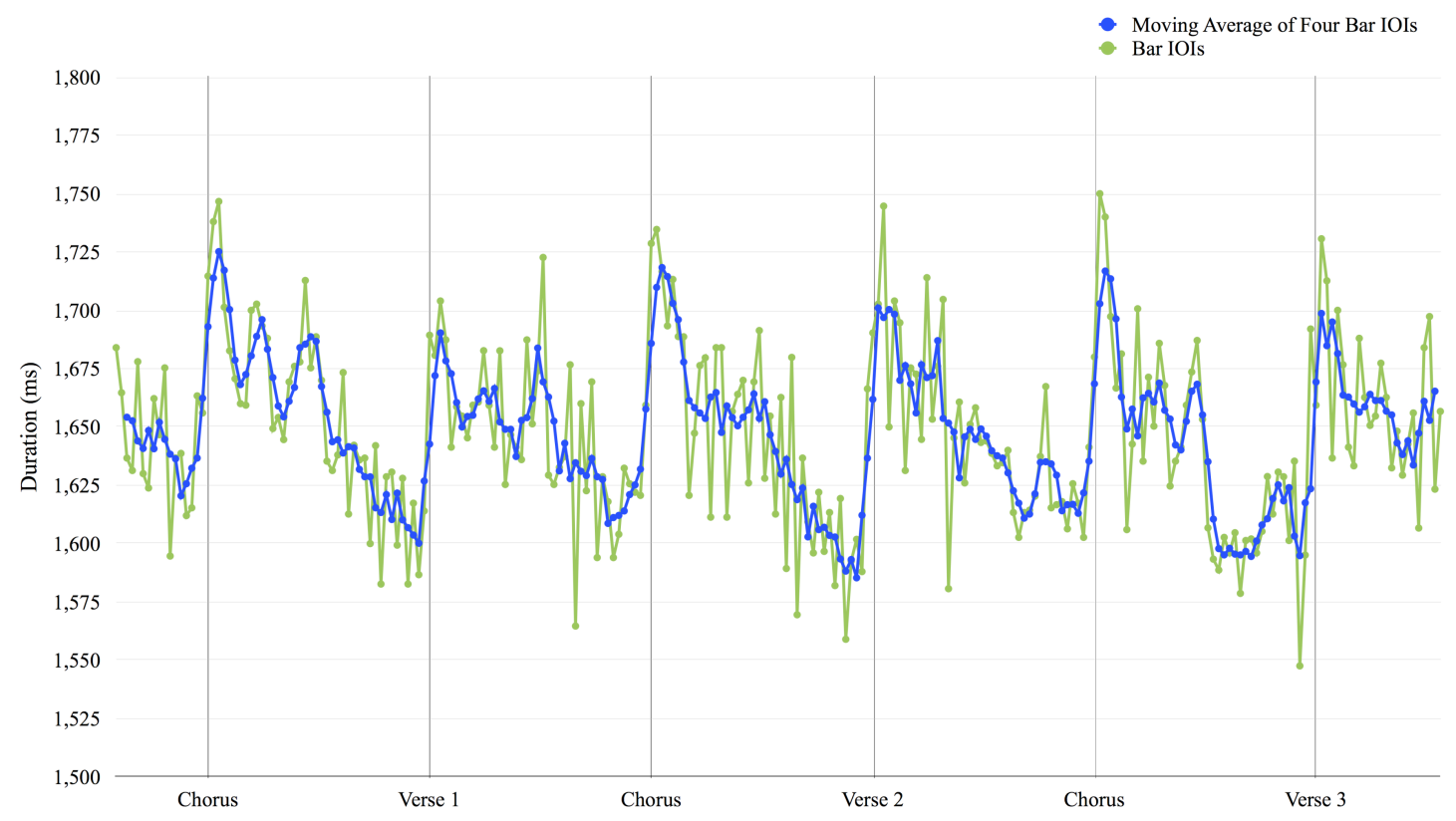

Figure 6. Individual bar IOIs in "Nazad, nazad, mome Kalino" and the moving average of the IOIs of four successive bars. Vertical lines mark the beginning of each vocal section.

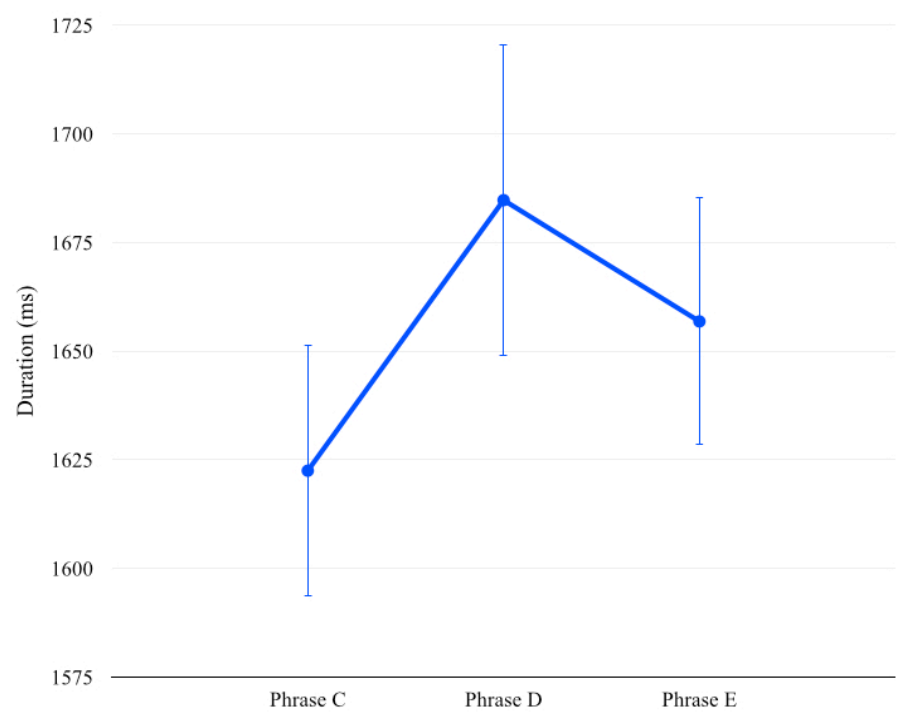

Figure 7. Mean bar IOIs for each phrase of "Nazad, nazad, mome Kalino." Vertical brackets show standard deviation.

The relationships among the three aksak beats, however, appear to differ between the two performances. Whereas the third beat is generally longer than the second in "Bešli i čaj tele," in "Nazad, nazad" the mean ratio of the second to the third beat is just barely greater than 1 and significantly different from the ratio of .92 for both phrases in Bizlim's recording taken together (see Appendix Table 2). Figure 8 offers a general comparison of the average IOIs for each of the three beats, pooling phrase A with phrase B and phrase $\mathrm{C}$ with phrase $\mathrm{E}$. I use these four phrases for the comparison rather than the complete performances in an effort to match the mean bar IOIs, as the mean bar IOI of phrase A, $1650 \mathrm{~ms}$, is close to that of phrase E, $1656 \mathrm{~ms}$, and the mean bar IOI of phrase B, $1623 \mathrm{~ms}$, is likewise close to that of phrase C, $1622 \mathrm{~ms}$. Pooling phrases with different bar IOIs also seems justified in that independent-samples $t$-tests 
reveal no significant differences between corresponding beat proportions within each performance (see Appendix Table 3). The resulting comparison between performances in Figure 8, though, indicates that Popov tends to play the first two beats of the measure a little longer than Bizlim does, with a shorter beat 3 making up the difference in the total length of the bar (see Appendix Table 4). These measurements place the proportions of Popov's three beats very close to the ideal 3:2 ratio of long and short aksak durations, with a ratio among the three beats of approximately 3:2.02:1.98, as opposed to 3:2.01:2.19 for Bizlim.

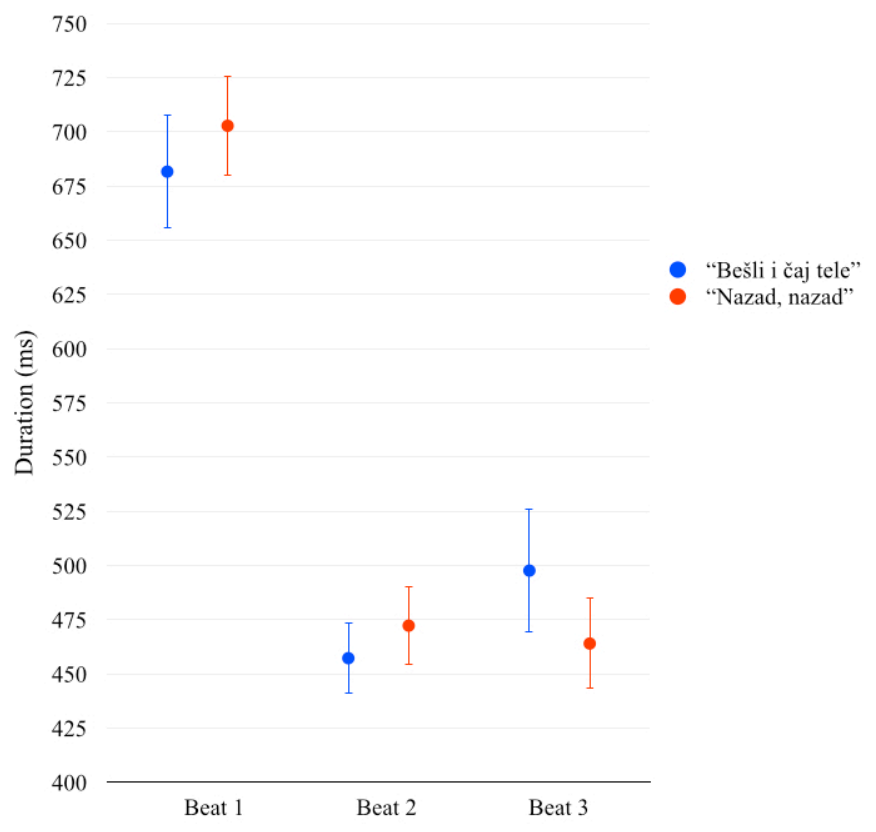

Figure 8. Mean beat IOIs in phrases A and B of "Bešli i čaj tele" and phrases C and E of "Nazad, nazad." Vertical brackets show standard deviation.

Potential accounts of this difference between the performances include the factors suggested above in connection with Bizlim's longer third beat: grouping, rhythm, and an underlying timing template. If the lengthening of the third beat in "Bešli i čaj tele" is a function of melodic grouping, the fact that Popov does not sing while drumming could mean that such local grouping does not impact his timing. Alternatively, the high rhythmic density of Popov's playing might work against a rhythmically determined imbalance by filling the span of each beat with an uninterrupted realization of the subtactus.

If the beat timing is not so dependent on particulars of grouping or rhythm, the difference could be shaped by aspects of the two musicians' differing backgrounds. For example, Popov's playing might approximate the 3:2 ratio because this is the theoretical norm that he was taught, and perhaps internalized, while studying at the conservatory, whereas Bizlim, though highly literate, has no formal musical training.[25] However, the difference might also be a more general feature of regional style that is not linked to training methods, as many Bulgarian musicians, in contrast with similar performers from Macedonia, reportedly follow timing that usually matches the theoretical ratio regardless of their education (Mark Levy, personal communication; Kalin Kirilov, personal communication).

\section{Ensemble Timing}

On the more detailed scale of individual phrases, Popov's timing still resembles Bizlim's in some respects, but interaction among musical participants stands out as an additional factor that could influence the variation in his IOIs. Two features of ensemble performance are notable in this connection: the polarity between soloistic playing for otsviri and accompanimental playing during singing, and Popov's coordination of these two techniques with the rest of the ensemble and with the singing and dancing audience. 
A basic distinction between the otsviri and the second vocal phrase manifests in measure-tomeasure timing. As in "Bešli i čaj tele," there are some differences among the mean IOIs of the beats in individual measures of phrase $\mathrm{E}$, but in phrase $\mathrm{C}$ none of the mean beat IOIs differ significantly based on their position in the phrase (see Appendix Table 5).[26] This general contrast might reflect the fact that Bulgarian tŭpan players recognize not only the two types of sections, but also the styles of playing that are appropriate for each one. For example, in teaching me rudimentary tŭpan technique, Zhivko Mihov, a musician from Provadiya, Bulgaria, introduced each aksak sequence with "basic" rhythms for accompanying singing and "solo" rhythms for otsviri. Whereas a basic rhythm such as the template in Figure 2 should clearly project low drum strokes on the beat to the rest of the ensemble, in teaching solo rhythms Mihov stressed the importance of offbeat accents played with the switch and improvised embellishments of the template.[27]

Such a difference between the rhythms that Popov plays during vocal phrases and otsviri can be heard on Audio Example 2. Figure 9 transcribes one of the rhythms that Popov uses most often during a single measure. While his performance includes many subtle variations of this pattern, the series of three beater strokes from the end of one measure to the beginning of the next stands out from the flurry of notes in the switch, clearly signaling the location of the downbeat for the other musicians and dancers. Mihov (personal communication) considers a pair of beater strokes on the downbeat and the following subtactus time point to be a characteristic feature of tŭpan rhythms for Macedonian songs including "Nazad, nazad," and indeed, Popov employs this three-note gesture throughout the performance. He does not play it equally often in all phrases, though: as indicated by the tallies in Table 3, the figure marks the downbeat of about two-thirds of the measures in phrases with a vocal melody, but only about one-quarter of measures in otsviri, which sound as though they exchange the figure for a variety of other, often syncopated patterns.

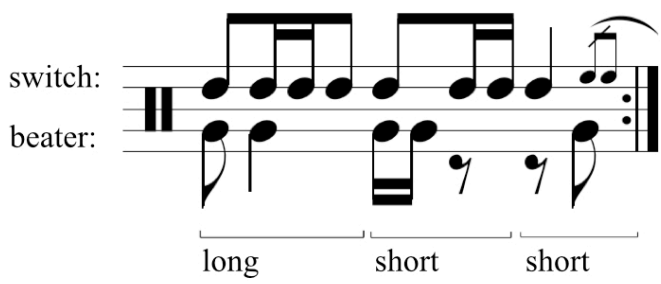

Figure 9. A transcription of one of the most frequent rhythms in a measure in Popov's performance of "Nazad, nazad."

Table 3. Tallies of measures with and without the downbeat figure in "Nazad, nazad."

\begin{tabular}{|c|c|c|}
\cline { 2 - 3 } \multicolumn{1}{c|}{} & \multicolumn{2}{c|}{ Downbeat Figure } \\
\cline { 2 - 3 } \multicolumn{1}{c|}{ Otsviri } & Present & Absent \\
\hline Vocal Phrases & 27 & 75 \\
\hline
\end{tabular}

Moving to the particulars of the timing variation that does occur in accompaniment for singing, Figure 10 shows the mean beat IOIs over the course of phrase E. The mean duration of the first beat in bar 8 is less than that in all other measures except for bars 2 and 7, while the first beats in these two measures are also shorter than beat 1 of bar 6 . Shortening near the end of the phrase also occurs in beat 3 , with the mean IOI in bar 7 less than in bars 1,2, and 3, and the mean IOI in bar 6 less than in bar 1. Despite the significance of its ANOVA, the second beat does not show any statistically significant differences over the course of the phrase; this minimal variability of beat 2 constitutes another similarity with "Bešli i čaj tele" (see Appendix Table 5). 


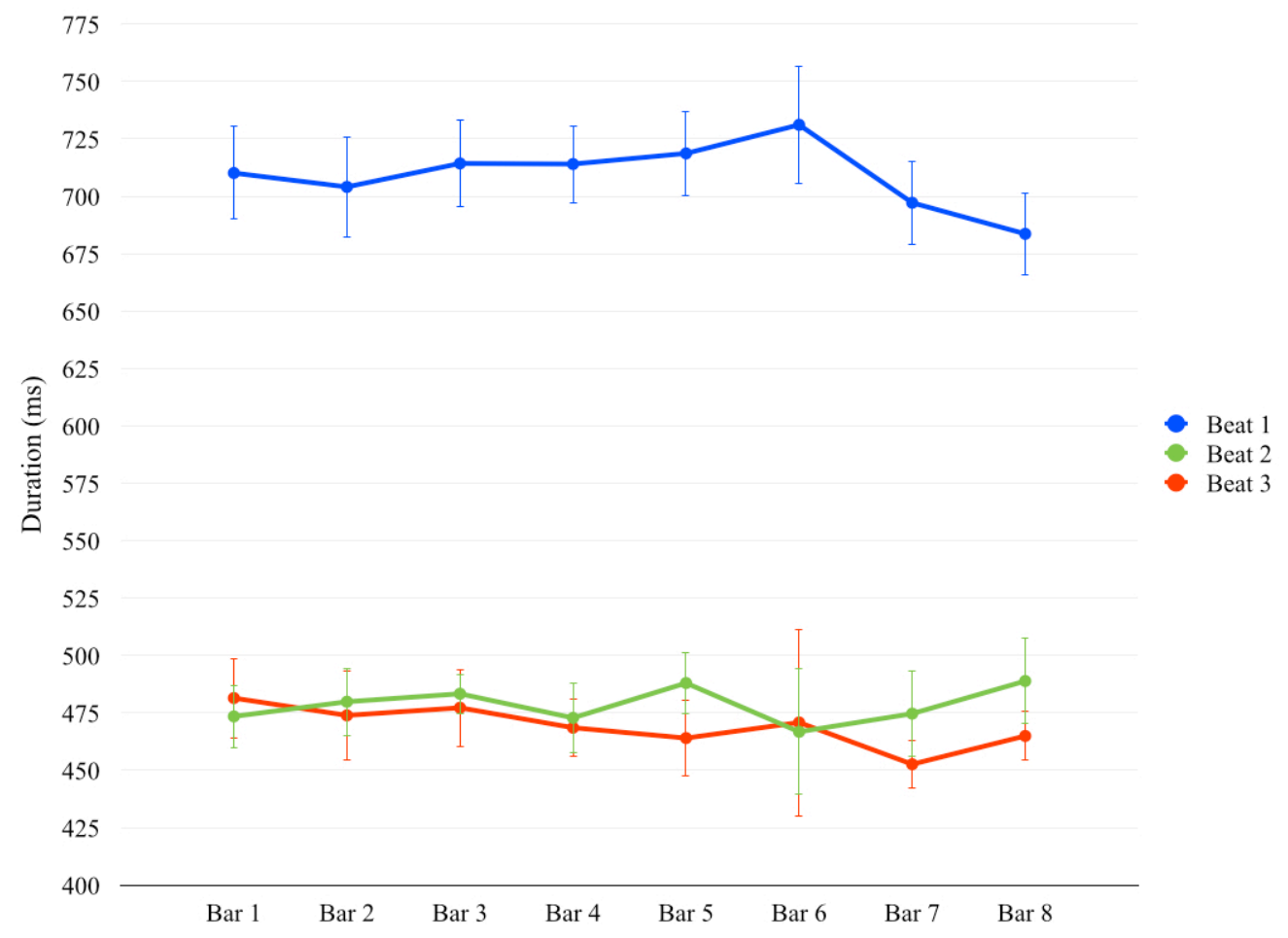

Figure 10. Mean beat IOIs in each bar of phrase E of "Nazad, nazad." Vertical brackets show standard deviation.

Whereas the presence or absence of local timing variability corresponds to the different approaches to drumming in vocal phrases and otsviri, some of the timing changes during accompanimental playing might have to do with coordination among the numerous people involved in the performance. For instance, the clearest change in phrase $\mathrm{E}$ is the shortening of IOIs in measures 7 and 8 . The last note of the melody begins on the downbeat of measure 7, and during these two bars without singing Popov breaks from his usual pattern for the rest of the vocal phrase, sometimes adopting a soloistic style suitable for an otsvir. The player of the gaida, the folk bagpipe that stands out among the pitched instruments throughout this recording, often comes in at this point as well, and of course, in half of the iterations of phrase E, these measures lead directly into the otsvir. However, this change might not be only a case of switching from the vocal to the instrumental mode of playing, but rather a particular technique signaling the end of the phrase, because Popov usually gives a conclusive gesture in measure 8 such as emphatic strokes with the beater on several successive eighth notes.

Accordingly, the pair of measures at the end of the phrase would serve as a point of orientation for all musical participants, ensuring that the group remains synchronized in transitioning to the next line of lyrics or the instrumental break. The idea that such a function could be fulfilled largely by the tüpan player, and perhaps also register in his or her timing, matches Popov's (personal communication) view of his role in the ensemble: he comments that the tüpan player is like a conductor, who should know the entire score and coordinate all the musicians and dancers. With regard to timing, the appearance of shorter IOIs at this point might also be related to the phenomenon of "cadential anchoring" that Ashley (2002, p. 320) identifies in performances of jazz ballads, whereby soloists tend to accelerate and more closely match the timing of their onsets with that of the bass player at cadences. As in the case of the other differences, though, the change in timing might or might not be deliberate on the part of the performer or detectable to a listener; what is noteworthy is its potential co-occurrence with meaningful musical action.

A similar pattern seems to manifest in the single added measure at the end of the otsvir, which has so far been absent from the analysis. While the small sample size of 6 occurrences makes it difficult to verify the assumption of normality required for parametric statistical tests, anecdotally the IOIs in this measure appear to depart from the consistent standard of the preceding measures in the otsvir. Table 4 compares a set of means and standard deviations for the extra measure-the mean IOIs for the three beats 
and the measure as well as the ratio of the second beat to the third beat-with the ranges of the same values for individual measures in the preceding eight bars of the otsvir. The final measure of the phrase seems to be longer than the preceding measures, with the elongation of the third beat as the clearest source of the difference. Especially since the second beat is also relatively short, this change makes for a mean ratio of beat 2 to beat 3 that is markedly lower than in the rest of the phrase.

Table 4. Comparison of mean bar and beat IOIs in the extra measure at the end of the otsvir in "Nazad, nazad" with the ranges of these means for individual measures in the preceding phrase.

\begin{tabular}{|c|c|c|c|c|}
\cline { 4 - 5 } \multicolumn{2}{c|}{} & \multirow{2}{*}{$\begin{array}{c}\text { Extra } \\
\text { Bar }\end{array}$} & \multicolumn{2}{c|}{ Preceding 8 Bars } \\
\cline { 3 - 5 } \multicolumn{2}{c|}{} & & Minimum & Maximum \\
\hline \multirow{2}{*}{ Bar IOI } & $\boldsymbol{M}$ & $1655 \mathrm{~ms}$ & $1604 \mathrm{~ms}$ & $1627 \mathrm{~ms}$ \\
\cline { 2 - 5 } & $\boldsymbol{S D}$ & $26 \mathrm{~ms}$ & $14 \mathrm{~ms}$ & $31 \mathrm{~ms}$ \\
\hline \multirow{2}{*}{ Beat 1 IOI } & $\boldsymbol{M}$ & $704 \mathrm{~ms}$ & $687 \mathrm{~ms}$ & $698 \mathrm{~ms}$ \\
\cline { 2 - 5 } & $\boldsymbol{S D}$ & $23 \mathrm{~ms}$ & $12 \mathrm{~ms}$ & $22 \mathrm{~ms}$ \\
\hline \multirow{2}{*}{ Beat 2 IOI } & $\boldsymbol{M}$ & $444 \mathrm{~ms}$ & $461 \mathrm{~ms}$ & $484 \mathrm{~ms}$ \\
\cline { 2 - 5 } & $\boldsymbol{S D}$ & $24 \mathrm{~ms}$ & $8 \mathrm{~ms}$ & $18 \mathrm{~ms}$ \\
\hline Beat 3 IOI & $\boldsymbol{M}$ & $506 \mathrm{~ms}$ & $447 \mathrm{~ms}$ & $460 \mathrm{~ms}$ \\
\cline { 2 - 5 } & $\boldsymbol{S D}$ & $20 \mathrm{~ms}$ & $7 \mathrm{~ms}$ & $19 \mathrm{~ms}$ \\
\hline \multirow{2}{*}{$\begin{array}{c}\text { Ratio of Beat 2 } \\
\text { to Beat 3 }\end{array}$} & $\boldsymbol{M}$ & .88 & 1.00 & 1.08 \\
\cline { 2 - 5 } & $\boldsymbol{S D}$ & .03 & .01 & .03 \\
\hline
\end{tabular}

The seeming elongation of the last measure of the otsvir is not surprising in light of the quick increase in bar IOIs at the beginning of each vocal section, as discussed above in connection with Figures 5 and 6. Indeed, the mean IOI of individual measures increases by another $68 \mathrm{~ms}$ to $1723 \mathrm{~ms}$ by the second measure of phrase D, making for a total change between averages of about $114 \mathrm{~ms}$ in the space of four bars - though again, the differences have not been checked for statistical significance in the manner of most others in this paper. In thus mediating the adjustment in timing between otsvir and singing, as well as in its position outside of the otherwise regular phrase rhythm, the last measure of the otsvir resembles the twobar transition in "Bešli i čaj tele."

As with the ends of vocal phrases, though, the extra measure also participates in a concluding gesture, with the phrase expansion underscoring the cadence at the end of the otsvir. This ending appears to serve a key function for coordinating the musical participants, prompting both the ensemble vocalist and the many audience members who know the words to begin singing again after the instrumental interlude, and the action of signaling this transition and ensuring that everyone comes in together could contribute to the general increase in bar IOIs as well as the particular lengthening at the end of the added measure. In fact, the local change in the third beat is reminiscent of the lengthening at two-bar grouping boundaries in "Bešli i čaj tele" when Bizlim takes a breath, so perhaps the alteration of the otherwise nearly constant relationship between the second and third beats corresponds to a collective breath right before the vocal entry. Interestingly, if this change in timing and that at the end of phrase $\mathrm{E}$ are both related to processes of ensemble coordination at cadences, as I have suggested, then the different directions of the respective timing shifts might reflect differences in the kinds of coordination taking place: lengthening IOIs when bringing the group together to start singing again, versus shortening when refocusing the ensemble's synchronization at more local endings.

\section{POSSIBILITIES}

As should be evident from the foregoing analysis, the present study does not aspire to draw firm conclusions about the nature of timing in Balkan percussion performance. Rather, it is in the spirit of a pilot study or proof of concept, with the goals of demonstrating that timing is a potentially fruitful subject for empirical research in this music and suggesting possible characteristics of timing that could be evaluated in future work.

The two considerably different examples of recorded performances thus exhibit timing variations that, though small, are consistent at parallel moments within a performance and appear to occur in 
conjunction with other musical features, especially melodic grouping and the coordination of musical participants. Accordingly, the specifics of melody or relative placement within a phrase may be relevant to fine-grained changes in aksak timing, because some of the changes reported in both recordings only manifest when IOIs are separated according to distinct melodies and positions in a phrase. Such specificity seems to support Popov's (personal communication) insistence that a percussionist must know and follow not only the basic sequence of long and short beats, but also the particular melody that he or she is accompanying. However, the ways in which percussion timing varies with particular phrases might depend on the drummer's relationship to the melodic performance. The apparent sensitivity of Bizlim's timing to local melodic grouping seems plausible considering that he is singing and tapping simultaneously. In Popov's performance, the association of most timing alterations with phrase endings immediately before or after collective singing could reflect the dynamics of maintaining synchronization among the many musical participants.

Both of these scenarios represent relatively unexplored areas of research. To my knowledge, experiments investigating the effect of concurrent singing on tapping control are absent from the extensive literature on sensorimotor synchronization, and while interest in the timing of ensemble performances has increased in recent years, most studies focus on timing asynchronies among members of an ensemble rather than individual or collective changes in successive IOIs.[28] These lacunae, like others in music psychology literature, might result from the difficulty of isolating particular explanations for complicated musical behaviors. Still, experimental manipulations and larger samples of existing recordings can certainly provide further evidence in relation to specific possibilities suggested here, such as the tendencies for lengthening during the last beat of a measure in conjunction with local grouping boundaries, sudden lengthening at the beginning of a large-scale vocal group, and lengthening or shortening of IOIs at phrase endings in connection with different functions of ensemble coordination.

In addition to improving understanding of the relationship of timing with grouping and ensemble coordination, the measurements reported here, if borne out by future work, have implications for theories of meter. Polak and London (2014, par. 107) have recently interpreted particular non-isochronous timing patterns as evidence for unequal durations in meter itself, suggesting the potential for a much larger spectrum of meters than standard systems of musical notation capture. Fine-grained timing on a given metric level is one way in which these many similar, stylistically specific meters might differ from one another. In the present case, the different overall relationships of beat IOIs in the two performances-a consistently unequal ratio between the second and third beats in "Bešli i čaj tele," as opposed to near conformity to the ideal 3:2 ratio in "Nazad, nazad"-could represent just this type of difference between meters.

However, the multiple levels of periodicity and other factors with which timing can vary also indicate that such potentially metric timing is not reducible to a single, fixed series of proportions; instead, metric timing might consist of a set of several interacting dimensions or a range of possibilities.[29] One way of expressing this irreducibility can be found in Danielsen's (2010, p. 29) and Johansson's (2009, pp. $243-248$; 2010) related concepts of "beat bins" and "rhythmic tolerance," which involve a temporal window during which a metric onset may occur or extend rather than a single point, but other approaches might be appropriate for musical styles other than the particular popular and folk repertoires that these two authors discuss. In any case, such metric timing would itself be only one component of meter.

Although the uncertainty of my account of timing in the two example recordings precludes generalization even to closely related performances, much less to other styles, the evaluation of these possibilities need not be limited to Balkan folk music. Apart from theoretical issues of relationships among aksak durations, many of the ideas that this study has generated about grouping, ensemble coordination, and meter could readily be adapted for testing in other musical styles. Along these lines, Huron (2013, pp. 6-7) even suggests that tests of hypotheses are stronger when the population sampled to form the hypothesis differs from the population used to test it. I hope this study has demonstrated, then, that Balkan music performances include fascinating patterns of timing, and hold the potential to improve our understanding of the performance of many musics.

\section{ACKNOWLEDGMENTS}

I am grateful to the many musicians whose comments are cited in this paper, and especially to Gregory Scarborough and Mitko Popov for granting permission to use the audio examples. Ian Quinn and Fernando 
Benadon gave sympathetic and insightful readings to earlier versions of the text. While these conversations and advice improved the study immeasurably, the remaining flaws are entirely my own responsibility.

This work was completed with generous support from a U.S. Student Fulbright Research Fellowship in Bulgaria.

\section{NOTES}

[1] Correspondence can be addressed to daniel.1.goldberg@gmail.com.

[2] Scarborough (2000) provides a translation of the lyrics. A different version of this song, from a recording made in 1961 in Štip, Macedonia, appears in Petrovski (2001, p. 74).

[3] Also known as Šutka, Bizlim's place of residence Šuto Orizari was established as a Romani housing area in 1963 by the Yugoslav government, and now might be the largest Romani neighborhood in the world (Silverman, 2000, p. 203; 2012, p. 12).

[4] Stover (2009, pp. 17-28) offers a justification for this use of "transcription-as-visual-aid."

[5] Both "Balkan" and "folk" are contested terms. For a discussion of cultural and colonial implications of the former, see Todorova (1997); for the wide-ranging musical and political uses of the latter in Bulgaria and the former Yugoslavia, see Buchanan (2006, pp. 33-45) and Silverman (2012, pp. 178-179).

[6] My statistical method is questionable on several counts. First, I have sifted through the timing data at length, which, as Huron (2013) explains, diminishes the reliability of tests of significance. Second, I compare different beats, measures, and phrases within a performance by treating them as samples from a population of repeatable musical actions that extends beyond that performance. This approach is consistent with a psychological perspective on musical behavior, but given that the samples come from a single, continuous performance, in some cases it might violate the assumption that the samples being compared are independent from one another, which is a necessary condition for the validity of my statistical tests. These tests also depend on the assumption that data values approximate a normal distribution, a property that is difficult to verify for small sample sizes. I use standard practices to examine the data for normality and impose a minimum sample size of 10 , but this is a liberal limit. Ad hoc procedures to address other concerns, such as unequal sample sizes, are described in connection with the results of particular statistical tests in the Appendix.

[7] Destanovski is the grandson of a well-known zurla player of the same name. The younger Željo also specializes in this double-reed instrument.

[8] Dragan Dautovski (personal communication), a leading Macedonian folk musician, gives the longshort-short sequence pride of place in his characterization of the close relationship between rhythm and language in Macedonian music: he considers the sequence to be distinctly Macedonian because it realizes a musical analogue to the pattern of stress on the antepenultimate syllable that typifies the Macedonian language, in contrast with the free stress of the closely related Bulgarian language.

[9] This instrument is known by several different names, including tapan in Macedonia, tŭpan in Bulgaria, and dauli in Greece. I adjust my terminology to the particular performer and style under consideration; accordingly, in this paper I use tŭpan. The same principle of following local conventions applies to transliterations from Macedonian and Bulgarian Cyrillic.

[10] As for the drum, there are several different names for the beater and switch, including kiyak and prǔcka, respectively.

[11] Yeston (1976) was significant in establishing the conception of meter in terms of multiple levels, but as Mirka (2009) shows, many other characteristics of this perspective can be found in writings from the late eighteenth century by Kirnberger and Koch. For an important contrasting theory of meter, see Hasty (1997). 
[12] As Lerdahl and Jackendoff's (1983, pp. 37-38) exposition of grouping organization makes clear, a comprehensive analysis of grouping would partition a piece into many nested groups ranging in length from less than one measure to the duration of the piece itself. Rather than laying out a complete grouping analysis, I discuss the groups of intermediate length that appear to be most relevant to timing.

[13] Bizlim stops tapping at the beginning of the fourth measure of the song's last phrase, so averages for IOIs in the fourth measure of phrase B include 11 instances instead of 12.

[14] Not all significant pairwise differences are described here; instead, test statistics, $p$ values, and pairwise differences for this and subsequent sets of tests are reported in the Appendix. Statistical tests were carried out using SPSS software.

[15] I am indebted to Ian Quinn for drawing my attention to this ambiguity.

[16] The most common term is "phrase-final lengthening," a borrowing from the field of linguistics, but I follow Ohriner (2012, par. 3) in preferring "group-final lengthening" to avoid confusion between linguistic and musical definitions of a phrase. Most studies of group-final lengthening describe not just any lengthening at the end of a group, but rather a specific lengthening of successive, conceptually equal durations that approximates a parabola. Especially since aksak beats by definition are not all conceptually equal, I do not attempt to test for the presence of parabolic timing changes here. Still, Ohriner (2012) regards series of performed durations as "reflective" of group-final lengthening if they match basic patterns of durational contour that need not be parabolic.

[17] For a study arguing for the historical contingency of such timing patterns, see Cook (2009).

[18] Another form of lengthening that might escape detection in measurements of tapping from this performance is the longer duration of the last note in the melody of each verse, which Bizlim sustains during the beginning of the transition.

[19] Further information about the workshop can be found on its website, www.folkseminarplovdiv.net. For a historical account of American interest in Balkan music as an outgrowth of the international folk dance movement of the mid-twentieth century, leading to the establishment of workshops like this one, see Laušević (2007).

[20] On the nature of stylistic changes in Bulgarian music in relation to influences including radio technology and the socialist political system, see Rice (1994) and Buchanan (2006). Buchanan (2006) describes the characteristics and specializations of Bulgaria's leading folk ensembles, including Ensemble Trakiya.

[21] For a detailed description of the movements of lesnoto and an analysis of structure underlying variations in these movements, see Leibman (1992, ch. 4). Although I do not discuss the connection of musicians' timing with dance, it is potentially a very important factor; for instance, tüpan players are often considered responsible for adapting the beat to dancers' movements (Jerry Kisslinger, personal communication; Keil et al., 2002, p. 81).

[22] On the character of otsviri in typical Bulgarian folk song performance, see Buchanan and Folse (2006, p. 66) and Buchanan (2006, pp. 93-96).

[23] Indeed, knowledgeable audience members often recognize a song in a medley by the tune of its opening otsvir, before hearing any singing.

[24] A one-way ANOVA indicates a significant effect of a bar's phrase in "Nazad, nazad" on its IOI, $F(2$, $117)=52.08, p<.01$. Because unequal sample sizes can increase the chances of incorrectly rejecting the null hypothesis, the test uses a random sample of 40 measures from each phrase. Tukey's HSD test finds significant differences among the mean IOIs in all three phrases. 
[25] Another way in which the 3:2 ratio could be learned is through practice with a metronome, but Popov (personal communication) does not use one.

[26] Phrase D and the extra measure at the end of the otsvir are not considered here due to their small sample sizes, but see below for a discussion of the latter.

[27] Like Popov, Mihov is educated in the Bulgarian conservatory system, having recently completed his training on gŭdulka, a folk string instrument. However, explicit knowledge of the two modes of playing seems not to be exclusive to musicians with formal training, as Rumen Randev (personal communication), a self-taught Romani percussionist from Kotel, Bulgaria, speaks of the same opposition.

[28] For recent reviews of these two bodies of research, see Repp and Su (2013) and Keller (2014). A study of ensemble performance that does report changing IOIs over time is Shaffer (1984).

[29] Similarly, Benadon (2006) argues that it is a mistake to search for a constant, universal swing ratio.

\section{REFERENCES}

Arom, S. (2004). L’aksak: Principes et typologie. Cahiers de Musiques Traditionnelles, 17, 11-48.

Ashley, R. (2002). Do[n’t] change a hair for me: The art of jazz rubato. Music Perception, 19(3), 311-332.

Benadon, F. (2006). Slicing the beat: Jazz eighth-notes as expressive microrhythm. Ethnomusicology, 50(1), 73-98.

Benadon, F. (2007). Commentary on Matthew W. Butterfield's "The power of anacrusis". Music Theory Online, 13(1).

Bengtsson, I., \& Gabrielsson, A. (1977). Rhythm research in Uppsala. Music, room, and acoustics (pp. 1956). Stockholm: Royal Swedish Academy of Music.

Brăiloiu, C. (1984). Aksak rhythm. In A. L. Lloyd (Ed.), Problems of ethnomusicology (pp. 133-167). Cambridge: Cambridge University Press.

Buchanan, D. A. (2006). Performing democracy: Bulgarian music and musicians in transition. Chicago: University of Chicago Press.

Buchanan, D. A., \& Folse, S. (2006). How to spin a good horo: Melody, mode, and musicianship in the composition of Bulgarian dance tunes. In M. Tenzer (Ed.), Analytical studies in world music (pp. 58-91). Oxford: Oxford University Press.

Butterfield, M. W. (2007). Response to Fernando Benadon. Music Theory Online, 13(3).

Butterfield, M. W. (2010). Participatory discrepancies and the perception of beats in jazz. Music Perception, 27(3), 157-175.

Cannam, C., Landone, C., \& Sandler, M. B. (2010). Sonic visualiser: An open source application for viewing, analysing, and annotating music audio files. Paper presented at the Association for Computing Machinery Multimedia 2010 International Conference, Florence, Italy.

Clarke, E. F. (1985). Structure and expression in rhythmic performance. In P. Howell, I. Cross \& R. West (Eds.), Musical structure and cognition (pp. 209-236). London: Academic Press.

Clarke, E. F. (1989). The perception of expressive timing in music. Psychological Research, 51(1), 2-9. 
Cler, J. (1994). Pour une théorie de l'aksak. Revue de Musicologie, 80(2), 181-210.

Cook, N. (2009). Squaring the circle: Phrase arching in recordings of Chopin's mazurkas. Musica Humana, l(1), 5-28.

Danielsen, A. (2010). Here, there and everywhere: Three accounts of pulse in d'Angelo's "Left and right". In A. Danielsen (Ed.), Musical rhythm in the age of digital reproduction (pp. 19-35). Farnham, UK: Ashgate.

Dzhudzhev, S. (1931). Rythme et mesure dans la musique populare bulgare. Paris: Librairie Ancienne Champion.

Dzhudzhev, S. (1980). Bŭlgarska narodna muzika: Uchebnik za bŭlgarskata dŭrzhavna konservatoriya (2 ed. Vol. 1). Sofia: Izdatelstvo "Muzika".

Friberg, A., Bresin, R., \& Sundberg, J. (2006). Overview of the KTH rule system for musical performance. Advances in Cognitive Psychology, 2(2-3), 145-161.

Gabrielsson, A. (1987). Once again: The theme from Mozart's Piano sonata in A major (K. 331): A comparison of five performances. In A. Gabrielsson (Ed.), Action and perception in rhythm and music (pp. 81-103). Stockholm: Royal Swedish Academy of Music.

Hasty, C. F. (1997). Meter as rhythm. New York: Oxford University Press.

Huron, D. (2013). On the virtuous and the vexatious in an age of big data. Music Perception, 31(1), 4-9.

Jankowsky, R.C. (2013). Rhythmic elasticity and metric transformation in Tunisian stambeli. Analytical Approaches to World Music, 3(1), 34-61.

Johansson, M. (2009). Rhythm into style: Studying asymmetrical grooves in Norwegian folk music. (Ph.D. thesis), University of Oslo.

Johansson, M. (2010). The concept of rhythmic tolerance: Examining flexible grooves in Scandinavian folk fiddling. In A. Danielsen (Ed.), Musical rhythm in the age of digital reproduction (pp. 69-83). Farnham, UK: Ashgate.

Keil, C., Keil, A. V., Blau, D., \& Feld, S. (2002). Bright Balkan morning: Romani lives and the power of music in Greek Macedonia. Middletown, CT: Wesleyan University Press.

Keller, P. E. (2014). Ensemble performance: Interpersonal alignment of musical expression. In D. Fabian, R. Timmers \& E. Schubert (Eds.), Expressiveness in music performance: Empirical approaches across styles and cultures (pp. 260-282). Oxford: Oxford University Press.

Laušević, M. (2007). Balkan fascination: Creating an alternative music culture in America. New York: Oxford University Press.

Leibman, R. H. (1992). Dancing bears and purple transformations: The structure of dance in the Balkans. (Ph.D. diss.), University of Pennsylvania.

Lerdahl, F., \& Jackendoff, R. (1983). A generative theory of tonal music. Cambridge: MIT Press.

London, J. (2012). Hearing in time: Psychological aspects of musical meter (2nd ed.). Oxford: Oxford University Press.

Mirka, D. (2009). Metric manipulations in Haydn and Mozart: Chamber music for strings, 1787-1791. New York: Oxford University Press. 
Moelants, D. (2006). Perception and performance of aksak metres. Musicae Scientiae, 10(2), 147-172.

Neuhoff, H., Polak, R., \& Fischinger, T. (2014). Perception of metric timing patterns in Malian jembe music. Paper presented at the Third Interntional Conference on Analytical Approaches to World Music, London.

Ohriner, M. S. (2011). Durational contours and enacted meaning in recorded performances of Chopin's piano music. (Ph.D. diss.), Indiana University.

Ohriner, M. S. (2012). Grouping hierarchy and trajectories of pacing in performances of Chopin's mazurkas. Music Theory Online, 18(1).

Peninta, K., Cambouropoulos, E., \& Papadelis, G. (2008). Quantitative investigation of temporal microdeviations in Greek asymmetric meters. [In Greek.] Paper presented at the Fourth Conference of the Hellenic Institute of Acoustics, Xanthi, Greece.

Petrovski, T. (2001). Romski narodni pesni od Makedonija. Skopje: Institut za Folklor "Marko Tsepenkov".

Pettan, S. (1996). Gypsies, music, and politics in the Balkans: A case study from Kosovo. World of Music, $38(1), 33-61$.

Polak, R. (2010). Rhythmic feel as meter: Non-isochronous beat subdivision in jembe music from Mali. Music Theory Online, 16(4).

Polak, R., \& London, J. (2014). Timing and meter in Mande drumming from Mali. Music Theory Online, 20(1).

Repp, B. H. (1992). Diversity and commonality in music performance: An analysis of timing microstructure in Schumann's “Traumerei”. Journal of the Acoustical Society of America, 92(5), 25462568.

Repp, B. H. (1998a). The detectability of local deviations from a typical expressive timing pattern. Music Perception, 15(3), 265-289.

Repp, B. H. (1998b). A microcosm of musical expression: I. Quantitative analysis of pianists' timing in the initial measures of Chopin's Etude in E major. Journal of the Acoustical Society of America, 104(2), 10851100 .

Repp, B. H., \& Su, Y. H. (2013). Sensorimotor synchronization: A review of recent research (2006-2012). Psychonomic Bulletin \& Review, 20(3), 403-452.

Rice, T. (1994). May it fill your soul: Experiencing Bulgarian music. Chicago: University of Chicago Press.

Rice, T. (2000). Béla Bartók and Bulgarian rhythm. In E. Antokoletz, V. Fischer \& B. Suchoff (Eds.), Bartók perspectives: Man, composer, and ethnomusicologist (pp. 196-210). Oxford: Oxford University Press.

Sachs, C. (1953). Rhythm and tempo: A study in music history. New York: W. W. Norton and Company.

Scarborough, G. (2000). The Shutka music project: Heartsongs from the gypsies of Shutka, Macedonia. Atlanta: Music that Matters.

Shaffer, L. H. (1984). Timing in solo and duet piano performances. Quarterly Journal of Experimental Psychology Section A:Human Experimental Psychology, 36(4), 577-595. 
Silverman, C. (2000). Researcher, advocate, friend: An american fieldworker among Balkan Roma, 19801996. In H. G. De Soto \& N. Dudwick (Eds.), Fieldwork dilemmas: Anthropologists in postsocialist states (pp. 195-217). Madison: University of Wisconsin Press.

Silverman, C. (2012). Romani routes: Cultural politics and Balkan music in diaspora. Oxford: Oxford University Press.

Stover, C. D. (2009). A theory of flexible rhythmic spaces for diasporic African music. (Ph.D. diss.), University of Washington.

Todd, N. (1985). A model of expressive timing in tonal music. Music Perception, 3(1), 33-57.

Todorova, M. (1997). Imagining the Balkans. New York: Oxford University Press.

Yeston, M. (1976). The stratification of musical rhythm. New Haven: Yale University Press.

\section{APPENDIX}

Appendix Table 1. One-way ANOVAs comparing the mean beat IOIs in each measure of the two phrases of "Bešli i čaj tele."

\begin{tabular}{|c|c|c|l|}
\hline Beat & F Statistic & $\boldsymbol{p}$ Value & \multicolumn{1}{c|}{ Tukey HSD Result } \\
\hline $\mathbf{1}$ & $F(7,87)=18.55$ & $<.01$ & $\begin{array}{l}M_{A 4}, M_{B 4}<M_{A 1}, M_{A 2}, M_{A 3}, M_{B 1}, M_{B 2}, M_{B 3} \\
M_{A 3}, M_{B 3}<M_{A 1}\end{array}$ \\
\hline $\mathbf{2}$ & $F(7,87)=4.12$ & $<.01$ & $M_{B 1}, M_{B 4}<M_{A 4}, M_{B 2}$ \\
\hline $\mathbf{3}$ & $F(7,87)=6.84$ & $<.01$ & $\begin{array}{l}M_{A 2}, M_{A 4}>M_{A 3}, M_{B 2}, M_{B 3} \\
M_{B 4}>M_{A 3}\end{array}$ \\
\hline \multicolumn{3}{|c|}{ Repetition without Verse 1 } \\
\hline $\mathbf{1}$ & $F(7,56)=16.74$ & $<.01$ & $\begin{array}{l}M_{A 4}, M_{B 4}<M_{A 1}, M_{A 2}, M_{A 3}, M_{B 1}, M_{B 2}, M_{B 3} \\
M_{B 3}<M_{B 1}\end{array}$ \\
\hline $\mathbf{2}$ & $F(7,56)=3.31$ & .01 & $M_{B 1}, M_{B 4}<M_{A 4}$ \\
\hline $\mathbf{3}$ & $F(7,56)=9.58$ & $<.01$ & $\begin{array}{l}M_{A 2}, M_{A 4}, M_{B 4}>M_{A 3}, M_{B 3} \\
M_{A 2}, M_{A 4}>M_{B 2} \\
M_{A 2},>M_{A 1}, M_{B 1}\end{array}$ \\
\hline
\end{tabular}

The $p$ values are adjusted using the Holm-Bonferroni correction for a set of 3 tests. For $p$ values less than .05 , Tukey's HSD test is used to estimate which means differ from one another, with subscripts denoting the phrase and bar number (e.g., $M_{A 3}$ indicates the mean for bar 3 of phrase A). Means and standard deviations are graphed in Figure 4. Since the mean bar IOI in verse 1 is longer than that of all other verses (see p. 309), the tests are repeated without the first verse to check for the effect of the longer measures, with results that are largely similar to those of the initial tests. 
Appendix Table 2. Several $t$-tests for the mean ratio of the second to the third beat IOI in "Bešli i čaj tele" and "Nazad, nazad, mome Kalino."

\begin{tabular}{|c|c|c|c|c|c|c|c|}
\hline Performance & Test Type & Sample & $\boldsymbol{N}$ & $\boldsymbol{M}$ & $\boldsymbol{S D}$ & $\boldsymbol{t}$ Statistic & $\boldsymbol{p}$ Value \\
\hline "Bešli i čaj tele" & One-Sample & All Bars & 107 & .92 & .06 & $t(106)=-14.33$ & $<.01$ \\
\hline "Bešli i čaj tele" & One-Sample & Random & 40 & .93 & .05 & $t(39)=-8.14$ & $<.01$ \\
\hline "Nazad, nazad" & One-Sample & All Bars & 246 & 1.02 & .06 & $t(245)=4.39$ & $<.01$ \\
\hline "Nazad, nazad" & One-Sample & Random & 40 & 1.01 & .07 & $t(39)=1.23$ & .23 \\
\hline $\begin{array}{c}\text { Comparison of } \\
\text { Performances }\end{array}$ & $\begin{array}{c}\text { Independent- } \\
\text { Samples }\end{array}$ & Random & $\begin{array}{c}40 \text { per } \\
\text { piece }\end{array}$ & \multicolumn{2}{|c|}{ as above } & $t(78)=-10.70$ & $<.01$ \\
\hline
\end{tabular}

Since the large numbers of observations potentially give this test higher power than most others reported here, one-sample tests are repeated using random samples of 40 measures from each performance. In the one-sample $t$-tests, a $p$ value of less than .05 indicates that the ratio is significantly different from 1 , while in the independent-samples $t$-test, a $p$ value of less than .05 indicates that the two means differ from each other.

Appendix Table 3. Independent-samples $t$-tests comparing mean beat IOIs as proportions of a measure in selected phrases of "Bešli i čaj tele" and "Nazad, nazad, mome Kalino."

\begin{tabular}{|c|c|c|c|}
\hline Phrases & Beat & $\boldsymbol{t}$ Statistic & $\boldsymbol{p}$ Value \\
\hline A and B & $\mathbf{1}$ & $t(93)=-.21$ & .84 \\
\cline { 2 - 4 } & $\mathbf{2}$ & $t(93)=-.81$ & .84 \\
\cline { 2 - 4 } & $\mathbf{3}$ & $t(93)=.82$ & .82 \\
\hline C and E & $\mathbf{1}$ & $\begin{array}{c}t(174.98)=1.07 \\
(\text { variances not equal })\end{array}$ & .57 \\
& $\mathbf{2}$ & $t(187)=-.32$ & .75 \\
\cline { 2 - 4 } & $\mathbf{3}$ & $t(187)=-.86$ & .78 \\
\hline
\end{tabular}

This within-performance comparison of beat proportions in pairs of phrases serves to justify the pooling of those phrases for the between-performance comparison reported in Appendix Table 4 and graphed in Figure 8. Since the pairs of phrases being compared have different mean bar lengths, the tests compare beat IOIs as proportions of a bar instead of bar IOIs in milliseconds. The values of the three beats are thus interdependent in the way that I describe on p. 310 and have sought to avoid in other statistical tests. The last measure of the otsvir (phrase C) is not included in these and subsequent tests of the beat IOIs in "Nazad, nazad," and 3 measures are excluded due to the presence of outliers. The $p$ values are adjusted using the Holm-Bonferroni correction for a set of 3 tests.

Appendix Table 4. Independent-samples $t$-tests comparing the mean beat IOIs in phrases A and B of "Bešli i čaj tele" with those in phrases C and E in "Nazad, nazad, mome Kalino."

\begin{tabular}{|c|c|c|}
\hline Beat & $\boldsymbol{t}$ Statistic & $\boldsymbol{p}$ Value \\
\hline $\mathbf{1}$ & $t(158)=-4.81$ & $<.01$ \\
\hline $\mathbf{2}$ & $t(158)=-6.63$ & $<.01$ \\
\hline $\mathbf{3}$ & $\begin{array}{c}t(128.80)=9.49 \\
\text { (variances not equal) }\end{array}$ & $<.01$ \\
\hline
\end{tabular}

To ensure equal sample sizes, the tests use random samples of 80 measures from each performance. The $p$ values are adjusted using the Holm-Bonferroni correction for a set of 3 tests. Means and standard deviations of the complete data set are graphed in Figure 8. 
Appendix Table 5. One-way ANOVAs comparing the mean beat IOIs in each measure of the two phrases of "Nazad, nazad, mome Kalino."

\begin{tabular}{|c|c|c|c|l|}
\hline Phrase & Beat & \multicolumn{1}{|c|}{$\boldsymbol{F}$ Statistic } & $\boldsymbol{p}$ Value & \multicolumn{1}{|c|}{ Tukey HSD Result } \\
\hline \multirow{3}{*}{ C } & $\mathbf{1}$ & $F(7,87)=.95$ & .48 & N/A \\
\cline { 2 - 6 } & $\mathbf{2}$ & $F(7,87)=2.18$ & .13 & N/A \\
\cline { 2 - 5 } & $\mathbf{3}$ & $F(7,87)=1.23$ & .59 & N/A \\
\hline \multirow{4}{*}{ E } & $\mathbf{1}$ & $F(7,87)=5.82$ & $<.01$ & $\begin{array}{l}M_{8}<M_{1}, M_{3}, M_{4}, M_{5}, M_{6} \\
M_{2}, M_{7}<M_{6}\end{array}$ \\
\cline { 2 - 5 } & $\mathbf{2}$ & $F(7,87)=2.36$ & .03 & No significant differences. \\
\cline { 2 - 5 } & $\mathbf{3}$ & $F(7,87)=4.42$ & $<.01$ & $\begin{array}{l}M_{7}<M_{1}, M_{2}, M_{3} \\
M_{6}<M_{1}\end{array}$ \\
\hline
\end{tabular}

The $p$ values are adjusted using the Holm-Bonferroni correction for a set of 3 tests. For $p$ values less than .05 , Tukey's HSD test is used to estimate which means differ from one another, with subscripts denoting the number of the bar (e.g., $M_{7}$ indicates the mean for bar 7). Means and standard deviations for phrase E are graphed in Figure 10. 